\title{
Research on Occupational Safety and Health Service of Migrant Workers under Discrimination
}

\author{
Xueying Yang ${ }^{1, a}$, Yanbin Wang ${ }^{2, b}$ and Jianding $\mathrm{Zhu}^{3, \mathrm{c}_{*}}$ \\ ${ }^{1}$ Southwest forestry university, yunnan, China \\ 2yunnan university, yunnan, China \\ ${ }^{3}$ Southwest forestry university, yunnan, China \\ a154057708@qq.com, b1091245620@qq.com, C529147431@qq.com
}

* The Corresponding author

Keywords: Migrant Workers; Social Responsibility; Service of Occupational Safety and Health

\begin{abstract}
The pursuit of equal citizenship is the basic rights of everyone. In practice, however, migrant workers and staff in the enterprise enjoy treatment of different citizens because of the influence of the structural and institutional factors. Whether in the occupational safety and health care, and occupational education on safety and health, or guarantee of workers' rights and interests, the case that" same work with different pay between migrant workers and staff "and" same work with different rights between migrant workers and staff" is still prominent.
\end{abstract}

\section{Introduction}

The migrant workers, as a social stratification, were born in the process of China's social structure transformation and urbanization. In addition to the basic survival needs, migrant workers want to launch an appeal for an equal citizenship to get higher level of demands. Although relevant enterprises have realized that it is very important to maintain the occupational health of staff, and also have taken some measures to improve the staff's working environment and conditions, but in fact they pay more attention to the field of occupational safety. Because the occupational health needs long-term investment and management, so the spirit is willing but the flesh is weak for enterprises.

How to ensure rights and interests on the occupational safety and health of the migrant workers is a real problem which enterprises have to solve now in the process of the transformation of peasant workers' identity. From a survey of current situation of rural migrant workers in occupational health services, In the face of these contradictions such as short-term interests and long-term interests, their own interests and the interests of the employees, the enterprises usually choose the short-term investment and self-interest behavior, the seeming rational behavior is hard to stand up in social responsibility in the future. Migrant workers with formal workers enjoy different treatment in the aspect of the right to health and life. Enterprises adopt different management systems according to types of employees, which is the objective requirement of the precision management. It is unfair to suffer discrimination partly because of their natural talent for migrant workers. From the point of view of ought to be, migrant workers and formal workers should enjoy the treatment of the "equal pay for equal work". In fact, the phenomena that "unequal pay for equal work" and "disparate treatment" are obvious in the process of service of occupational safety and health. Formal workers usually get more supports and better service than what migrant workers get in occupational safety and health, occupational health and education, and occupational health protection. In terms of division of labor, most of the formal workers tend to work as managers; almost the whole migrant workers are assigned to the forefront of production in their enterprises. Disparate treatment between migrant workers and formal workers is manifested in the following aspects: occupational safety and health, occupational health and education, and occupational health protection. 
The conclusion of this paper is based on relevant investigation, this research is conducted through survey and target at employees, out of the total 550 questionnaires; I receive 501 valid questionnaires (260 formal employees, 241 migrant workers) with the valid return rate as $91 \%$.Furthermore, the author try to explain the results of the data by interviews survey to he head of the relevant enterprise managerial level and relevant government departments and twenty migrant workers. Interview samples including the head, head of the government management, enterprise related management and over 20 migrant workers.

\section{Care of the Occupational Safety and Health}

Occupational safety and health of migrant workers is mainly manifested in ensuring safety in production and provides a security infrastructure and mechanism Security infrastructure and mechanisms mainly includes physical examination of migrant workers and occupational diseases controlling and prevention systems, health and safety of workplace. The present study finds that organizing regular physical examination of migrant workers is a thorny problem. Work hour of migrant workers is affected by the project duration, so migrant workers need to find a new job once the time limit arrives. Liquidity of migrant workers' job is the main influence that enterprise shoulder social responsibilities to implement regular physical examinations of the rural migrant workers. At the same time, the company offers for each migrant workers industrial injury insurance during work period, although which is basic occupational safety and health services for migrant workers, but enterprises are facing an embarrassing situation. The cause is that the work who migrant workers are engaged in have liquidity, temporality, seasonality, and dangerousness, so that the enterprise offer for each migrant workers injury insurance may be impossible or undesirable - or both. What shall we do is not how to develop systems and Procedures, but is how to implement a system effectively.

In the process of labor protective measures involves the use of protective equipment, work environment, work conditions, risk control, security operation system, supply and use of shield, Occupational health professionals, protective settings in the poisonous and harmful workplace, the use of good protective material, application of new technology etc. According to the survey, in protective equipment, migrant workers are mainly equipped with basic protective equipments such as masks, ear plugs, helmet, gloves, common drugs, etc. In fact, the common protective equipments can not eliminate occupational disease such as electric eye, pneumoconiosis and silicosis effectively. Take the noise of rolling mills and dynamic power plants as examples, only the noise transmitted outside of workshop can be muted, the noise transmitted in the workshop cannot be muted, so workers is inevitable to suffer the noise. Enterprises must increase more investment in the introduction of new technology, new equipment in order to reduce the degree of occupational hazards. So far, from rational utilitarian perspective, the small and medium-sized enterprise without rich enough money often will not choose to introduce advanced protective equipment to protect worker safety and health. Perhaps, these small and medium-sized enterprises also have no ability to invest largely to improve the worker's safety and health services.

The difference of occupational health measures between individuals and departments is obvious. Although three are operation procedures on production, rules and regulations and other institutional rules, the protection of occupational health are influenced from systems, technology, work experience, and individual cognitive level. Some enterprises take very drastic measures in the process of supervision to punish the conduct such as breaches of discipline, violation of agreements and disregard of law. Both involved companies and persons shall be punished by a fine or warning. Of course, because some migrant workers have lucky psychology and think it troublesome, so they are reluctant to equip themselves with protective clothing in their work without effective supervision. Some branches have not been equipped with basic infirmary because of remote location, so workers have to go to the hospital a few miles away from their branches. Moreover, 
escort vehicle is not professional ambulance, but a common vehicle. In order to pay little cost, these plants usually choose to recruit more young workers.

Monitoring archives of occupational health are settled up. Monitoring archives of occupational health is not only a documentary evidence for safety accident claiming, but also is a proof that braches can supervise health situation of workers in real time and improve their management effectively. The cause Why some enterprise do not build monitoring archives of occupational health includes two aspects, the one aspect is that enterprise do not pay insufficient attention, the other aspect is that job characteristic of migrant workers influence the continuity of archives. The management of monitoring archives of occupational health is facing a problem of breaking away from workers themselves because of characteristic and mobility of job. Some enterprises think that it is unnecessary to build health archives for short-time workers, some enterprises think that building health archives will increase enterprises' cost, and the other enterprises think that building health archives will set up a barrier to shirk responsibility. How to build health archives is a real problem to resolve timely for enterprise.

\section{The Occupational Health Education}

Receiving the occupational health education is the basic rights and interests of each professional worker. Enterprise can offer regulatory occupational safety education for formal workers. But for a large number of migrant workers, the type of occupational health education that "master train an apprentice" is very prevalent, because the type has flexibility, popularity and efficiency, but some workers is very excellent without instruct of the famous master under the education mode. Level of occupational safety and health protection is obvious between individuals under the education mode. Although there is a production operation procedures, rules and regulations and other institutional regulation, but protection of occupational health processing is affected by system, technology level, work experience, and individual cognitive level. What the enterprise can do is to strengthen education of occupational safety; the situation of occupational health education is overwhelmingly negative. Enterprise is the main organizers and executants of training on occupational safety and health at present. Perception of occupational safety and health from Both business leaders and peasant workers' are all limited to occupational safety, they only know the result of what has hurt his own body; but they do not know the cause of hurting, and they do not know how to guard against the harm lack of good education. The goal of occupational safety and health education is to cultivate the consciousness of migrant workers on occupational safety and health and the ability to cope with the quality of occupational hazards.

Although some enterprises have realized that it is very important to pay attention to occupational safety for enterprises itself, and has taken action to ensure the safety in the process of production, but for the occupational health, enterprise lack of strong motive power to ensure occupational health because the investment is long-time, high-risk and high-cost.

Even if some enterprises have taken some action in occupational health, their mechanisms also do not take effect for job's liquidity and short-term of rural workers. At the same time, emphasis on physical health of occupational health is not drew enough attention, the education practice of mental health in enterprises isn't worth mentioning, so the occupational health education for enterprises seems to be a reluctant choice. Of course, enterprise is the prime organizers, and the government, community, non-governmental organizations all are important impetus in America and Germany during the education of occupational health. In the United States, the governments also take a variety of instructive measures, including consulting services, education training of safety and health and information services besides the mandatory measures. In addition, community, trade unions, non-governmental organizations also carry out cooperation with enterprises on the occupational safety and health education under the sponsorship of the government. 


\section{Protection of Rights and Interests in Occupational Health}

Protection of rights and interests in occupational health is the focus of contradiction between labor and capital in enterprise. According to "the law on the prevention and control of occupational diseases", the enterprises (employers) should protect those who may suffer from occupational diseases, in strict accordance with the relevant provisions, enterprises should arrange occupational health examination for who may suffer from occupational diseases when they start, take office and leave office . Enterprises should pay for a check-up for the whole migrant workers. In fact, the check and review of occupational disease and rehabilitation of the migrant workers is far from optimistic. Some migrant workers even have realized that some occupation will inevitably lead to occupational safety and health risks and hidden trouble, but they still choose high hazard industry in order to survive. Those who engage in high-risk industry usually has low knowledge level, low professional skill and low level of self-awareness. This group, compared with other professional group, they undertake more social risks brought by the labor-intensive industries, they receive more exploitation than what other professional group receive. Some enterprises deliberately recruit migrant workers in order to decrease the cost of prevention and control in occupational diseases because of non-symmetry of information, and with no need for signing labor contracts. Some migrant workers confirmed as occupational diseases still work for their enterprises. According to relevant law, employers once find occupational patients or the patient concerned, they should promptly report to the administrative department of public health, and they should report to the administrative department for labor security under the circumstance of occupational injury. From the investigation and research, We find that providing false and concealing material are common things for employers. Especially after occupational injury accident, the head of enterprise should be responsible for the accident, so work injury compensation is usually resolved through dialogue and consultation between employers and employees; and the law can not ensure employees' interests. Migrant workers are not in a good position in the process of pursing profit because of their poor negotiation skills and ability, so the force of law is weakened.

In the occupational health examination and diagnosis, there are many problem at present, for example, projects of inspection are imperfect; the rate of the re-inspection is low; Occupational history, total work length and length of service projects such as tuberculosis in the check-up is not complete. In addition, most of the doctors in charge are from other clinical professional without physician qualification of occupational-disease diagnosis. Some check-up on occupational-disease is merely formal, only for a task, most of the items checked are irrelevant with occupation, and some check-up is organized while workers know nothing about check-up. Migrant workers can not timely receive results of check. Enterprises usually deliberately conceal patient's condition. Many physical examinations are arranged in the common hospitals, which have no qualification to occupational disease diagnosis certificate.

Companies also have recognized the difference between occupational safety and occupational health, first, the enterprises set up a security administrator, in recent years enterprises begin to set up full-time occupational health administrator, whose duty is mainly in charge of supervision and inspection on production safety. From the top to the first line of management personnel, they pay more attention to safety in production, yet occupational health especially occupational health of migrant workers haven't received little attention in the process of management practices.

According to relevant system, enterprises must establish health archives for each employee and organize regular occupational health examination during their work, but in fact, some enterprises can not perform their duties. In addition, the occupational safety and health facilities must conform to the standards prescribed by the laws, these health facilities shall be designed, built, together with the principal part of the project at the same time. 


\section{Conclusion}

There are disparate treatments between formal workers and migrant workers; on the one hand, enterprises have no choice but to do, on the other hand, some enterprises lack strategic judgment. Service abilities of Enterprise are limited in supervision of occupational safety and health, occupational safety and health education, and protection of occupational safety three practice fields. Enterprises provides migrant workers with disparate treatment in occupational safety and health services, at the same time, they also set up obstacles for future advancement. If enterprises pursue long-term development, they must ensure occupational safety and health without extra serious accident, but they usually can't guarantee for a high risk industry enterprises. From the reality, many enterprises still can not perform "safety first" ideology, and the implementation of the occupational health has a long way to go.

\section{Acknowledgement}

This research was financially supported by by the ministry of education planning fund project "research on enterprise implementation mechanism of the migrant workers' occupational health service management" (10 yja840043).

\section{References}

[1]Bo Shu: Social Scientist, (2010).

[2] Anping Fan: Vocational and technical education of the rural migrant workers : the experience and enlightenment of developed countries ", "education academic journal, (2013), no.4.

[3]Changliu Jing, Fanting Li: Research on health economic, (2014), no.7.

[4] Song Wang: Journal of yunnan administration college, (2014), no.2.

[5] Yanbin Wang, Xueying Yang: Journal of jiangsu administration institute, (2015), no.6.

[6] Weigang Wu, Tianli Jian and Qiong Luo: "China" Journal of industrial medicine,vol.2 (2014) p.27. 